Economics Development Analysis Journal

\title{
Analisis Persistensi Inflasi Jawa Tengah
}

\section{Poppy Erviyana ${ }^{1 凶}$}

PT. World Innovative Telecommunication (OPPO), Indonesia

\begin{tabular}{|c|c|}
\hline Info Artikel & Abstrak \\
\hline $\begin{array}{l}\text { Sejarah Artikel: } \\
\text { Diterima Januari } 2016 \\
\text { Disetujui Maret } 2016 \\
\text { Dipublikasikan Mei } 2016\end{array}$ & $\begin{array}{l}\text { Tujuan dari penelitian ini adalah Untuk mengukur dan mengetahui tingkat persistensi inflasi umum } \\
\text { serta menghitung dan mengetahui jangka waktu yang diperlukan untuk kembali ke tingkat } \\
\text { alamiahnya.Variabel dalam penelitian ini yaitu inflasi umum Jawa Tengah periode tahun } 2008 \\
\text { hingga 2013. Metode penelitian yang digunakan adalah model autoregressive. Berdasarkan penelitian } \\
\text { diperoleh hasil olah data menggunakan Eviews } 6 \text { dapat diketahui bahwa persistensi inflasi umum di }\end{array}$ \\
\hline $\begin{array}{l}\text { Keywords: } \\
\text { Inflation persistence, General } \\
\text { Inflation, Inflation } \\
\text { Commodities Group, } \\
\text { Autoregressive. }\end{array}$ & $\begin{array}{l}\text { Jawa Tengah tergolong tinggi yaitu } 0.85 \text {. Serta waktu yang dibutuhkan inflasi untuk kembali ke } \\
\text { tingkat alamiahnya yaitu selama } 6 \text { bulan. Adapun saran dari penelitian ini antara lain diharapkan } \\
\text { melalui Tim Pengendali Inflasi Daerah (TPID) terdapat semacam kebijakan yang bisa mengontrol } \\
\text { inflasi agar efek shock dapat diantisipasi yaitu dengan membuat lalu lintas produksi dan distribusi } \\
\text { khusus kelompok komoditas penyusun inflasi yang dihubungkan per Kabupaten Provinsi Jawa }\end{array}$ \\
\hline
\end{tabular}

\begin{abstract}
The aim of this research is to measure and determine the level of general inflation then calculate and determine the duration needed to diminish to the natural level. The variable in this research is general inflation in Central Java from 2008 to 2013. The method used is the model of autoregressive time series. Based on the results of the research using Eviews 6, the data showed that persistence of general inflation in Central Java is high, it is 0.85. As well as the time required to diminish the inflation back to natural level requires long time, they are 6 months. The suggestion from this study are expected through Inflation Control Team Regional (TPID) make some kind of policy that could control the inflation of foodstuffs in order to effect the shock can be anticipated that by making the traffic production and distribution of specialty food commodity linked per regency of Central Java province. To anticipate the effects of shock as a result of extreme weather may cooperate with the Meteorology and Geophysics Agency (BMKG) in monitoring and weather forecasting as an ingredient of the policy formulation.
\end{abstract}

(C) 2016 Universitas Negeri Semarang

\footnotetext{
Alamat korespondensi:

Gedung Perkantoran Landmark Pluit, Lt.6 - 7, Blok B No 01 Jln

Pluit Selatan Raya, Pluit, Penjaringan Jakarta Utara - 14450

E-mail: poppyerviyana@ymail.com
} ISSN 2252-6765 


\section{PENDAHULUAN}

Ketimpangan atau kesenjangan pertumbuhan ekonomi saat ini mejadi salah satu permasalahan yang dihadapi oleh bangsa Indonesia dalam melaksanakan pembangunan, baik yang terjadi antar daerah maupun kesenjangan di dalam daerah sediri. Ketimpangan ekonomi sering dijadikan sebagai indikator perbedaan pendapatan perkapita ratarata, antar kelompok tingkat pendapatan, antar kelompok lapangan kerja, dan atau antarwilayah.

Sebagai salah satu kasus ketimpangan ekonomi di Provinsi Jawa Tengah. Di provinsi ini terjadi peningkatan dalam pertumbuhan ekonomi, namun pertumbuhan tersebut tidak diikuti dengan pemerataan pendapatan setiap kabupaten. Sebagian daerah di Provinsi Jawa Tengah misalnya Kota Semarang, Kabupaten Cilacap, Kabupaten Kudus, Kota Surakarta, dan Kota Magelang, memiliki pendapatan perkapita yang sangat tinggi namun di daerah lainnya yang memiliki pendapatan perkapita yang sangat rendah. Kabupaten yang memiliki pendapatan perkapita yang relatif rendah yaitu: Kabupaten Wonosobo, Kabupaten Grobogan, Kabupaten Purbalingga, Kabupaten Tegal, Kabupaten Kebumen. Ketimpangan tersebut dapat terlihat dari perbedaan karakteristik wilayah Indonesia dalam hal kepemilikan sumber daya alam (SDA), sumber daya manusia (SDM), kondisi sosial dan budaya serta letak wilayah demografis wilayah tersebut. Maka tidak mengherankan bila pola pembangunan ekonomi diberbagai wilayah di Indonesia tidak seragam (Wijaya, 2001).

Masih terjadiya ketimpangan ekonomi di Jawa Tengah ini bila dilihat dari ketenagakerjaan. Menurut Aktivitas kerja sebagai faktor ekonomi dan kesejahteraan emosional penduduk (Bazzhina, 2015), akan tetapi terjadi ketidakseimbangan antara angkatan kerja dengan lapangan kerja yang tercipta sehingga menimbulkan masalah pengangguran. Pengangguran yang semakin besar akan menjadi beban perekonomian daerah dan mengurangi kesejahteraan masyarakat. Pada tahun 2003 jumlah pengangguran di Provinsi Jawa Tengah adalah sebanyak 912.513 orang, mengalami peningkatan menjadi sebanyak 1.044 .573 orang tahun 2004, dan menjadi lebih besar lagi pada tahun 2005 yaitu sebanyak 9.698 .112 orang (BPS, Jawa Tengah Dalam Angka, 2006). Masalah ini juga terjadi di Lithuania, Uni Eropa. Berdasarkan data dari badan statistik Lithuania, tercatat bhwa sejak tahun 2008, tingkat pengangguran meningkat baik di pedesaan dan kota-kota (Raisien et al., 2014).

Selain angkatan kerja, faktor yang memengaruhi pembangunan ekonomi daerah adalah dana bantuan pembangunan daerah. Alokasi anggaran pembangunan sebagai instrumen untuk mengurangi ketimpangane konomi tampaknya lebih perlu diperhatikan. Strategi alokasi anggaran tersebut harus mendorong dan mempercepat pertumbuhan ekonomi nasional sekaligus menjadi alat untuk mengurangi kesenjangan/ketimpangan regional (Majidi, 1997).

Proses akumulasi dan mobilisasi sumbersumber berupa akumulasi modal, keterampilan tenaga kerja dan sumber daya alam yang dimiliki oleh suatu daerah merupakan pemicu dalam laju pertumbuhan ekonomi wilayah yang bersangkutan. Adanya heterogenitas dan beragam karakteristik suatu wilayah menyebabkan kecenderungan terjadinya ketimpangan antardaerah dan antarsektor ekonomi suatu daerah. 
Tabel 1. Pencapaian Sasaran Inflasi Indonesia

\begin{tabular}{ccc}
\hline Tahun & $\begin{array}{c}\text { Sasaran Inflasi } \\
(\%)\end{array}$ & $\begin{array}{c}\text { Inflasi Aktual } \\
(\%, \text { yoy })\end{array}$ \\
\hline 2008 & $5 \pm 1$ & 11.06 \\
2009 & $4.5 \pm 1$ & 2.78 \\
2010 & $5 \pm 1$ & 6.96 \\
2011 & $5 \pm 1$ & 3.79 \\
2012 & $4.5 \pm 1$ & 4.30 \\
2013 & $4.5 \pm 1$ & 8.38 \\
\hline
\end{tabular}

Sumber : BankIndonesia,www.bi.go.i

Hal tersebut dapat dilihat pada Tabel 1 yang menunjukkan antara sasaran inflasi dan inflasi aktual di Indonesia dari tahun ke tahun. Sasaran inflasi yang tidak tepat, dapat menimbulkan banyak spekulasi yang berdampak negatif bagi perekonomian serta dapat mengurangi kredibilitas Bank Indonesia (Hakim dkk, 2012). Berdasarkan kondisi tersebut serta mengingat betapa pentingnya penetapan sasaran inflasi dalam rangka kestabilan perekonomian, maka penting pula untuk mengetahui perilaku dari inflasi itu sendiri yang nantinya dapat dijadikan sebagai referensi perumusan kebijakan dan juga sebagai koreksi kebijakan yang telah dilaksanakan. Ekspektasi inflasi merupakan elemen penting dalam analisis kebijakan moneter (Lei et al., 2015).

Perilaku inflasi dapat diketahui dari persistensi dari inflasi itu sendiri. Persistensi Inflasi adalah berapa lama kecepatan yang diperlukan oleh inflasi untuk kembali ke kondisi semula setelah terjadinya goncangan atau shock, tingkat kecepatan tinggi menunjukkan bahwa tingkat persistensi inflasi rendah sebaliknya tingkat persistensi inflasi tinggi di tunjukkan oleh lamanya tingkat inflasi kembali ke level ekuilibriumnya (Hakim dkk, 2012). Goncangan atau shocks merupakan suatu kondisi yang menyebabkan keadaan ekonomi menjauh dari posisi alamiahnya, perhitungan atau pengukuran dari persistensi inflasi diperlukan untuk melihat kecenderungan cepat lambatnya pergerakan tingkat inflasi untuk kembali ke nilai normalnya ketika terkena imbas kejutan atau shocks (Hidayati, 2013).

Kajian maupun penelitian tentang persistensi inflasi banyak difokuskan pada skala nasional, inflasi nasional terbentuk dari inflasi daerah, sehingga penelitian tentang inflasi di tingkat regional atau daerah sangat diperlukan (Hakim dkk, 2009). Penelitian persistensi inflasi di tingkat daerah dilakukan dengan mempertimbangkan bahwa masing-masing daerah memiliki karakteristik yang berbeda-beda sehingga menyebabkan adanya kebijakan pengendalian inflasi yang berbeda pula. Sebagai gambaranya, inflasi di Jawa Tengah dalam kurun waktu 2008 sampai dengan 2013 juga dipengaruhi oleh faktor yang bersifat kejutan (shocks). Faktor yang bersifat kejutan (shocks) yang mempengaruhi inflasi di Jawa Tengah dalam kurun waktu 2008 sampai dengan 2013 tersebut antara lain berupa tingginya harga minyak dunia dan pangan, kenaikan harga Bahan Bakar Minyak dalam negeri, pesta Pilpres, kondisi cuaca dengan curah hujan tinggi, bencana alam erupsi gunung Merapi, bencana banjir serta faktor musiman seperti tahun ajaran baru, puasa dan lebaran (Bank Indonesia. 2008-2013).

Berdasarkan deskripsi shocks di atas, maka perlu pengkajian lebih lanjut apakah shocks- shocks tersebut dapat menimbulkan persistensi inflasi 
yang tinggi di provinsi Jawa Tengah atau tidak. Berdasarkan pada uraian tersebut maka sangat penting untuk mengetahui pola perilaku inflasi di Jawa Tengah. Penelitian mengenai persistensi inflasi di Jawa Tengah dapat dilakukan pada inflasi umum. Sehingga dapat diketahui tingkat kecepatan inflasi untuk kembali ke nilai alamiahnya setelah timbulnya guncangan atau shock, guna menjadi referensi dalam merumuskan kebijakan serta sebagai alternatif peramalan dalam menetapkan target inflasi. Hal tersebut perlu dipertimbangkan agar inflasi yang telah ditargetkan oleh Bank Indonesia beserta pemerintah dapat mensejahterakan masyarakat bukan justru menjadi pemicu permasalahan perekonomian misalnya seperti masalah kemiskinan.

\section{METODE PENELITIAN}

Penelitian ini menggunakan pendekatan kuantitatif. Melalui penelitian ini, peneliti berusaha untuk mengimplementasikan teori dengan berdasarkan pada data atau bisa disebut juga dengan penelitian teori empiris dengan didasarkan pada data sekunder. Penelitian ini menggunakan jenis data sekunder dalam bentuk time series inflasi IHK umum di Jawa Tengah. Data time series yang digunakan dalam penelitian ini mempunyai periode waktu bulanan dari bulan Januari 2008 hingga Desember 2013. Data yang digunakan dalam penelitian ini bersumber dari Bank Indonesia, Badan Pusat Statistik (BPS) dan sumber lain yang relevan.

Langkah awal dalam penelitian ini adalah dengan melakukan uji stasioneritas pada data. Untuk menguji stasioneritas data, diantaranya adalah dengan menggunakan uji akar unit (Unit Root Test) yang dikembangkan oleh Dickey-Fuller. Prosedur untuk menentukan apakah data stasioner atau tidak dengan cara membandingkan antara nilai statistic Augmented
Dicky Fuller (ADF) dengan nilai kritisnya distribusi statistic Mackinnon (pada $\alpha=5 \%$ ). Jika nilai mutlak ADF statistik lebih besar dari Mackinnon Critical Value maka dapat disimpulkan series tersebut stasioner, sebaliknya jika nilai mutlak ADF lebih kecil dari Mackinnon Critical Value maka data tidak stasioner.

Selanjutnya estimasi persistensi inflasi dilakukan dengan melihat proses univariate autoregressive. Persistensi inflasi diartikan sebagai kecepatan tingkat inflasi untuk kembali ke tingkat ekuilibriumnya atau kenilai alamiahnya setelah timbulnya suatu shock. Persistensi inflasi dikatakan tinggi apabila tingkat inflasi saat ini sangat dipengaruhi oleh nilai lag-nya, sehingga koefisiennya mendekati 1 . Persamaan di atas di estimasi dengan menggunakan metode Ordinary Least Square (OLS). Nilai $\rho$ (Persistensi Inflasi) yang mendekati angka satu menunjukkan derajat persistensi inflasi tinggi berarti jangka waktu yang dibutuhkan untuk kembali kenilai alamiahnya membutuhkan waktu yang cukup lama. Sebaliknya jika nilai $\rho$ menjauh dari angka satu menunjukkan darajat persistensi inflasi yang rendah sehingga jangka waktu yang dibutuhkan untuk kembali ke nilai alamiahnya hanya sebentar. Setelah diketahui derajat persistensi Jawa Tengah maka selanjutnya dilakukan penghitungan untuk mengetahui jangka waktu yang dibutuhkan inflasi untuk kembali kenilai alamiah setelah adanya shock.

\section{HASIL DAN PEMBAHASAN \\ Persistensi Inflasi}

Berdasarkan hasil uji stasioneritas, data yang digunakan dalam penelitian ini menunjukkan bahwa data sudah stasioner. Untuk lebih lengkapnya dapat dilihat pada Tabel 2 sebagai berikut. 
Tabel 2. Hasil Uji Akar Unit terhadap Variabel Inflasi

\begin{tabular}{llll}
\multicolumn{5}{c}{ (Indeks Harga Konsumen Umum) } \\
\hline Variabel & Nilai Kritis & ADF Statistik (level) & $\begin{array}{l}\text { ADF Statistik (first } \\
\text { difference) }\end{array}$ \\
\hline Indeks Harga & $1 \%=-3.528515$ & -3.035166 & -6.03679 \\
Konsumen & $5 \%=-2.904198$ & (Prob 0.0366) & (Prob 0.0000) \\
Jawa Tengah & $10 \%=-2.589562$ & & \\
\hline
\end{tabular}

Sumber : diolah Eviews 6

Sebelum melakukan analisis, harus diketahui terlebih dahulu apakah data runtut waktu yang digunakan sudah stasioner. Berdasarkan hasil uji akar, dapat dilihat bahwa nilai ADF Stastisik lebih besar dari nilai kritisnya. Hal ini dapat disimpulkan bahwa variabel Indeks Harga Konsumen umum (IHK) stasioner.

Berdasarkan hasil pengujian dengan menggunakan software Eviews 6 diketahui bahwa koefisien autoregresif (AR (1)) bernilai 0.85. Nilai tersebut menunjukkan mendekati angka 1 (satu), yang berarti bahwa tingkat persistensi inflasi Jawa Tengah tergolong tinggi dengan nilai 0.85 . Tingginya persistensi inflasi Jawa Tengah juga menunjukkan bahwa waktu yang dibutuhkan inflasi untuk kembali kenilai alamiahnya adalah cukup lama setelah timbulnya suatu shock. Adapun hasil pengujian persistensi inflasi tersebut dengan data Indeks Harga Konsumen (IHK) inflasi umum yang diolah menggunakan software Eviews 6 akan ditampilkan dalam output sebagai berikut pada Tabel 3 .

Tabel 3. Hasil Pengujian Persistensi Inflasi

\begin{tabular}{ll}
\multicolumn{2}{c}{ Umum Jawa Tengah } \\
\hline Variabel & Coefficient \\
& \\
\hline $\mathrm{C}$ & 124.6949 \\
$\mathrm{AR}(1)$ & 0.85 \\
\hline
\end{tabular}

Sumber: diolah Eviews 6

Inflasi yang terjadi di Jawa tengah cenderung disebabkan karena faktor cost pushinflation atau faktor sisi penawaran, karena inflasi yang terjadi dipicu oleh adanya shock akibat pengaruh cuaca atau alam yang dapat menurunkan produksi (BPS, 2013). Pengaruh alam yang dimaksut seperti banjir, cuaca ekstrem yang terjadi di Jawa Tengah selama kurun waktu 2008 hingga 2013 dan bahkan bencana alam seperti bencana erupsi Gunung merapi di tahun 2010 yang menyebabkan pasokan maupun distribusi terganggu yang dapat menyebabkan adanya kelangkaan dan pada akhirnya menimbulkan kenaikan harga.

Berdasarkan diskripsi di atas, maka dapat disimpulkan bahwa inflasi di Jawa Tengah tahun 2008 sampai 2013 sejalan dengan teori inflasi strukturalis. Teori ini memberi tekanan pada ketegaran dari suatu strktur perekonomian negara-negara berkembang. Karena inflasi dikaitkan dengan faktor-faktor strktural dari perekonomian yang bisa berubah secara gradual dan dalam jangka panjang, serta faktor-faktor jangka panjang mana yang mengakibatkan inflasi berlangsung lama. Hal ini sejalan dengan Jawa Tengah yang merupakan salah satu provinsi yang ada di Indonesia dan Indonesia tergolong negara yang sedang berkembang. Inflasi di negara berkembang, menunjukan bahwa inflasi bukan hanya semata-mata merupakan fenomena moneter, tetapi juga merupakan fenomena struktural atau dapat juga karena faktor cost push inflation (Atmadja, 1999). Hal ini disebabkan karena struktur ekonomi di Indonesia termasuk provinsi Jawa Tengah umumnya masih bercorak agraris. Akibatnya jika terjadi goncangan atau shock pada ekonomi dalam negeri misalnya 
karena faktor cuaca ekstrem dan bencana alam yang menimbulkan instabilitas harga.

\section{Jangka Waktu yang dibutuhkan Inflasi untuk Kembali kenilai Alamiahnya Setelah Adanya Shock}

Setelah dilakukan perhitungan dengan rumus, diketahui bahwa waktu yang dibutuhkan inflasi di Jawa Tengah tergolong cukup lama, yaitu dimana inflasi umum membutuhkan waktu selama 6 (enam) bulan untuk kembali ketingkat alamiahnya.

Semakin lamanya waktu yang dibutuhkan inflasi untuk kembali ke nilai alamihnya, maka persistensi inflasinya juga makin tinggi. Demikian pula sebaliknya jika semakin besar derajat atau tingkat persistensi inflasi, maka waktu yang dibutuhkan inflasi untuk kembali ketingkat alamiah setelah adanya shock juga akan semakin lama. Lamanya inflasi Jawa Tengah untuk kembali ketingkat alamiah setelah adanya suatu shock, menunjukkan guncangan atau shock yang terjadi pada saat itu terhadap inflasi sulit dihilangkan atau sulit dinetralisir pada saat berlangsungnya inflasi. Karena sulit dihilangkan maka pengaruh shock tersebut akan berimbas pada kondisi inflasi di waktu mendatang. Jika hal tersebut terus menerus terjadi ketika pengaruh shock lama belum hilang kemudian muncul shock baru kembali, maka inflasi akan sulit dikendalikan serta menimbulkan ketidakakuratan dalam penargetan inflasi. Hal inilah yang membuat perhitungan mengenai waktu yang diperlukan oleh inflasi tersebut untuk kembali ke nilai alamiahnya sebelum terjadinya suatu shock menjadi sangat penting.

Oleh karena itu, penelitian mengenai perhitungan seberapa lamanya waktu yang dibutuhkan inflasi untuk kembali ketingkat alamiahnya berguna untuk mengetahui rentang waktu (dalam hitungan bulan) yang dibutuhkan inflasi tersebut untuk kembali ketingkat alamiahnya atau sebelum terkena shock atau guncangan. Sehingga waktu tersebut nantinya dapat dijadikan acuan atau bahan pertimbangan dalam penargetan inflasi serta perumusan kebijakan yang berkaitan dengan inflasi. Hal tersebut perlu dipertimbangkan, mengingat inflasi aktual di Indonesia kurang dari angka angka target bahkan lebih cenderung melampaui angka target yang telah ditetapkan. Inflasi Indonesia Terbentuk atas inflasi regional.

\section{SIMPULAN}

Setelah dilakukan penelitian mengenai persistensi inflasi di Jawa Tengah, maka dari hasil penelitian tersebut diperoleh kesimpulan bahwa inflasi umum di Jawa Tengah memiliki tingkat persistensi yang tinggi, yaitu sebesar 0.85.

Waktu yang dibutuhkan oleh inflasi umum untuk kembali pada nilai alamiahnya setelah adanya shock yaitu selama 6 (enam) bulan.

Sebaiknya, melalui Tim Pengendali Inflasi Daerah (TPID) bersama dengan pemerintah terdapat semacam kebijakan yang bisa mengontrol inflasi agar efek shock dapat diantisipasi yaitu dengan membuat lalu lintas produksi dan distribusi (ekspor impor domestik antar daerah) per kelompok komoditas pembentuk inflasi yang dihubungkan per Kabupaten Provinsi Jawa Tengah. Untuk mengantisipasi efek shock akibat cuaca ekstrem, dapat melakukan kerja sama dengan Badan Meteorologi dan Geofisika (BMKG) dalam hal monitoring dan peramalan cuaca sebagai bahan perumusan kebijakan tersebut.

Perlu dilakukan penelitian lanjutan mengenai faktor-faktor yang menyebabkan persistensi inflasi di Jawa Tengah tinggi hingga level komponen komoditas. Serta efektivitas Tim Pengendali Inflasi Daerah (TPID) dalam menangani masalah inflasi di Jawa Tengah.

\section{DAFTAR PUSTAKA}

Arimurti, Trinil dan Trisnanto, Budi. 2011. Persistensi Inflasi Di Jakarta dan Implikasinya Terhadap Kebijakan Pengendalian Inflasi Daerah. Buletin Ekonomi Moneter dan Perbankan.

Atmadja, Adwin S. 1999. Inflasi di Indonesia: Sumber - Sumber Penyebab dan Pengendaliannya. Jurnal Akuntansi dan Keuangan. 
Badan Pusat Statistik. Indeks Harga Konsumen dan Inflasi Jawa Tengah. Semarang.

Bank Indonesia. 2015. Koordinasi Pengendalian Inflasi. www.bi.go.id. (09 Juli 2015).

Bank Indonesia Semarang. 2010. Penelitian Persistensi di kota Semarang dan Implikasinya Terhadap Perekonomian Daerah.

Bank Indonesia. Kajian Ekonomi Regional (KER) Jawa Tengah. Semarang.

Bazzhina, V., 2015. Labour Activity As A Factor Of Social, Economic And Emotional Well-Being Of The Population. Procedia-Social and Behavioral Sciences, 166, pp.74 - 81.

Boediono. 1992. Ekonomi Moeneter. Yogyakarta: BPFE.

Charysa, N. (2013). Pengaruh Pertumbuhan Ekonomi Dan Inflasi Terhadap Upah Minimum Regional Di Kabupaten/Kota Provinsi Jawa Tengah Tahun 2008-2011. Economics Development Analysis Journal, 2(4). doi:10.15294/edaj.v2i4.2489

Hakim, Rachman, dkk. 2012. Kredibilitas Bank Sentral Dan Persistensi Inflasi Di Indonesia. Jurnal Ekonomi dan Keuangan.

Haryati, D. (2014). Analisis Inflasi Pra Dan Pasca Krisis Moneter Dalam Perekonomian Indonesia. Economics Development Analysis Journal, 3(2). doi:10.15294/edaj.v3i2.3848.

Hidayati, Fatimah. 2013. Analisis Persistensi Inflasi Jawa Timur: Suatu Pendekatan Sisi Penawaran.

Ismail, Maqdir. 2009. Bank Indonesia dalam Perdebatan Politik dan Hukum. Yogyakarta: Navila Idea.

Kelompok Kerja Nasional Tim Pengendalian Inflasi Daerah. 2013. Laporan Pelaksanaan Tugas. Jakarta: Kelompok Kerja Nasional TPID.

Khalwaty, Tajul. 2000. Inflasi dan Solusinya. Jakarta: Gramedia Pustaka Utama

Lei, C., Zhe Lu \& Zhang, C., 2015. News On Inflation And The Epidemiology Of Inflation Expectations In China. Economic Systems, 39, pp.644 - 653.

Lubis, Nurul. "Analisis Pengaruh Kebijakan Moneter Dan Kebijakan Fiskal Regional Terhadap Stabilitas Harga Dan Pertumbuhan Ekonomi Di Jawa Tengah (Periode 20012010)." Economics Development Analysis Journal [Online], 1.1 (2012): n. pag. Web. 1 Feb. 2016
Majidi, N. 1997. Anggaran Pembanguna dan Ketimpangan Ekonomi Antar Daerah. Prisma 3 LP3ES.

Marques, Robalo Carlos. 2005. Inflation Persistence: Facts or Artefacts. Economic Bulletin. Banco de portugal.

Purwoko, Bayu Agung, Yurastika, Feny. 2011. Analisis Persistensi Inflasi Daerah : Studi Kasus Sumatera Barat.

Putri, R. (2015). Analisis Inflasi, Pertumbuhan Ekonomi Dan Upah Terhadap Pengangguran Terdidik Di Provinsi Jawa Tengah Tahun 2009-2013. Economics Development Analysis Journal, 4(2). doi:10.15294/edaj.v4i2.6736.

Raisien, G., Bagdonien, J. \& Bilan, Y., 2014. Interinstitutional Interaction Results: The Effect Of Eu Programs on the Reduction of Long Term Unemployment. Procedia Economics and Finance, 16, pp.641 - 650.

Wijaya, Tunggal. 2001. Pengukuran Kinerja dengan Balanced Scorecard. Jakarta: Harvarindo. 